\title{
CRÍTICA DA CRÍTICA: ARTE DA EXISTÊNCIA E PROJEÇÃO TEÓRICA
}

\author{
Pedro Plaza Pinto ${ }^{1}$
}

\begin{abstract}
Resumo: A continuidade do interesse de Paulo Emilio Salles Gomes pelas manifestações da crítica de cinema, a partir das suas intervenções da década de 1960, conduz a um alto grau de reflexividade na sua própria escrita. $O$ pensamento sobre a atividade implica, então, uma escrita de si. Entretanto, trata-se de uma figuração transformadora que procura alterar a própria imagem da autoridade reconhecida, ao contrário da vontade de fixação que é mais comum para a construção da autoria.
\end{abstract}

Palavras-chave: Crítica; Salles Gomes; Autoria

\begin{abstract}
The continuity of Paulo Emilio Salles Gomes' interest for cinematographic critique's manifestations, from their interventions in the 1960's decade, leads to a high degree of reflexivity in his own writing. The thought about the activity implies, then, a self writing. However, it concerns a transformative figuration that attempts to alter the very image of recognized authority, as opposed to the fixation desire, which is more common in the authorship construction.
\end{abstract}

Keywords: Critique; Salles Gomes; Authorship

\section{Introdução}

Durante quase todo o século XX, a crítica de cinema foi uma instância privilegiada de construção de discursos sobre os meios massivos de comunicação e o seu impacto na sociabilidade moderna e no conhecimento científico. A crítica se inscreve de modo próprio entre os três estados do espírito científico em sua formação moderna, do concreto ao abstrato, pelo intermédio do estado concreto-abstrato (Bachelard, 1996: 11). Desde quando o psicólogo alemão Hugo Munsterberg, em 1916, estabeleceu uma conexão entre os filmes e estudos sobre atenção e percepção, baseando-se nas conquistas da narratividade de materiais da nascente indústria do cinema, a teoria e a crítica não cessam a mútua troca de impressões.

$\mathrm{O}$ esforço no alcance do estado abstrato enfrenta dificuldades com o realismo ingênuo e com os rápidos atravessamentos e transformações históricas dos últimos cem anos.

\footnotetext{
${ }^{1}$ Professor do Departamento de História da Universidade Federal do Paraná. Possui mestrado em Comunicação pela Universidade Federal Fluminense e doutorado em Ciências da Comunicação pela Universidade de São Paulo. Foi professor do curso de cinema da Faculdade de Artes do Paraná (FAP). Atua principalmente nas áreas de história, crítica e estética cinematográfica. Participou voluntariamente do projeto de descrição analítica do Arquivo de Paulo Emilio Sales Gomes, na Cinemateca Brasileira.
} 
Por ser a mídia paradigmática da modernidade que vai do automóvel ao foguete espacial (Aumont, 2008), o cinema reteve e enfrentou os desdobramentos implicados na vertiginosa expansão das mediações técnicas. Do telégrafo à rede mundial de computadores, do rádio ao disco de armazenamento de dados numéricos, a cada novo abalo a representação repensava a si própria e os modos de produção de filmes ganhavam incrementos, seja dentro do sistema industrial dos estúdios, seja em propostas artísticas que incrustravam funções artesanais de intervenção na matéria que ainda assim depende do trabalho especializado de fábrica. O jogo de polarizações admite muitas flutuações entre a prática da arte e a técnica de um Stan Brakhage ou de um George Lucas.

Além do aspecto histórico dos meios de representação, sobretudo ficou marcada a trajetória do cinema no século pela constante presença importada, em larga escala e mundialmente, dos materiais oriundos dos estúdios estadunidenses. Este aspecto propriamente social definiu a concentração da exibição vinculada a interesses comerciais de toda ordem. Este complexo sistema articula estética, economia e política necessariamente na mesma problemática, gerando a dificuldade de um pensamento de caráter mais geral, do esforço de totalização que também está entre as tarefas da crítica.

A primeira geração que questionou a estandartização do olhar e da escuta segundo paradigmas do teatro e do romance do século XIX foi justamente aquela que propôs, não sem muito idealismo estético, a elevação do cinema à categoria de arte (Xavier, 1978). Trata-se de realizadores, estetas e da nascente crítica de cinema que imantou as vanguardas históricas da década de 1920 e foi justamente a primeira a chamar sistemanticamente a atenção para a necessidade de preservação e resgate de filmes e práticas de realização fílmica - tanto para o interesse das futuras gerações, mas sobretudo como conteúdo renovador da própria prática artística.

Tendo como referência esta geração que sofreu com a implantação do filme sonoro, geração da qual aprendeu muitas lições, Paulo Emilio Salles Gomes atravessa trinta anos de presença constante como crítico e especialista em cinema, desde a sua sessão de cinema na revista Clima, do início da década de 1940, até os textos no Jornal da Tarde ou em Movimento, nos anos 1970. Quando chegou o momento da grande crise criativa e econômica do sistema industrial dos estúdios, que vai de meados da década de 1950 a meados da década de 1970, o então conservador da Cinemateca Brasileira é a mais reconhecida autoridade local no conhecimento da história do cinema. Tendo estado na França em dois períodos, estudado a obra do diretor francês Jean Vigo, participado ativamente dos debates da consolidação da 
Federação Internacional de Arquivos Fílmicos, Paulo Emilio é lido com grande interesse por todas as vertentes do cinema realizado no Brasil.

O objetivo desta contribuição é analisar a conformação de uma autoimagem de crítico e especialista que o trabalho tardio da sua escrita gerou. A principal referência é o importante texto O Cinema no século, publicado nas páginas do Jornal do Brasil no mês de dezembro de 1970. É pertinente à discussão apresentada por demarcar de modo pioneiro o campo de estudos da fruição e do gosto do público cinematográfico, além de apontar uma mudança qualitativa do próprio fenômeno cinematográfico em meio a outras mídias e práticas de consumo. Elabora, portanto, uma conexão entre cinema e sociedade, na tinta de uma intervenção crítica, com uma análise histórica que se inicia incluindo a si próprio dentro do arco temporal da consolidação e ocaso de um público da cultura de massa. O texto produz um balanço das tensões históricas envolvidas no trânsito entre gerações e modos de encarar o fenômeno cinematográfico. Tal análise elucida um universo de possibilidades que estas tensões produziriam, possibilidades em jogo no momento mesmo da escrita do texto. Em outras palavras, perfaz o movimento de investigação que parte do concreto para a construção do abstrato, chegando ao patamar das projeções teóricas.

Este tipo de análise, dedicada ao estudo de tendências e apropriações nas disputas do campo cinematográfico e dos meios massivos, já tinha precedentes, por exemplo, no ensaio $A$ obra de arte na era da reprodutibilidade técnica, escrito por Walter Benjamin entre 1937 e 1938 (Benjamin, 1984). O mesmo autor produzira anteriormente o brilhante ensaio em forma de montagem literária, Rua de mão única, (Benjamin, 1985). Do mesmo período, $O$ Ornamento da massa (Kracauer, 2009) também elabora uma abordagem renovadora da figuração do intelectual na confusa paisagem urbana. São materiais com um tipo de visão que, admitindo ainda as tendências em jogo, produz análises que colocam numa perspectiva projetiva a luta política que evidentemente ocorre na apropriação das potencialidades econômicas e estéticas das mídias de massa.

\section{Autoridade posta em questão: escrita de si e figuração cambiante}

Antes de expor artigos antecedentes e o texto mencionado, cabe apresentar mais detidamente quem foi Paulo Emilio Salles Gomes. Intelectual da geração formada entre as primeiras turmas da Faculdade de Filosofia, Ciências e Letras da Universidade de São Paulo, do grupo ligado ao Clube de Cinema, o qual liderou, e também à revista Clima. Teve no modernismo a referência para o período de sua formação nos anos 1930. Preso pela polícia 
política do Estado Novo na onda de repressão que se seguiu à intentona comunista, escapou da prisão cavando um túnel com seus colegas e depois partiu para a França, onde, em contato com ex-revolucionários e socialistas libertários, vira um especialista nos processos de Moscou. Com o retorno ao Brasil e ingresso na Faculdade de Filosofia, constitui a equipe que leva adiante a revista Clima, ao lado de Décio de Almeida Prado, Antonio Candido de Mello e Souza e Lourival Gomes Machado. Após o final da Guerra, parte novamente para a Europa e torna-se correspondente do segundo Clube de Cinema e representante na Federação de Arquivos. O primeiro Clube de cinema funcionara como encontro de discussão do grupo de Clima e fora também proibido pela polícia política. No exterior, escreve artigos como correspondente em festivais de cinema, trava contato com Andre Bazin e com o cinema italiano do período do Neo-realismo e produz um vigoroso estudo da obra do cineasta falecido precocemente, Jean Vigo, resgatando, reunindo e recuperando as películas do mesmo, então em vias de desaparecimento.

Quando retorna definitivamente ao Brasil, em 1954, é recebido como especialista, tido como uma espécie de taumaturgo no conhecimento sobre o cinema, cineclubismo, cinematecas e estética cinematográfica. Entre 1956 e 1963, escreve regularmente na seção de cinema do Suplemento Literário do jornal O Estado de São Paulo, contribuição que formou a consciência da necessidade da existência local de arquivos fílmicos, dos estudos históricos e da renovação da cultura cinematográfica local.

Em 1960, Paulo Emilio já era respeitado pelo seu trabalho como especialista em cinema e como conservador da Cinemateca Brasileira. Num contexto que já reconhecia o seu trabalho e a sua autoridade, ele foi posto diante do surgimento do grupo de jovens do Cinema Novo, entre os quais alguns se intitulavam orgulhosamente seus discípulos. Foi submetido ao teste de reconhecimento de estreias importantes, convocado a depor num tribunal sumário de gostos e juízos estético-históricos.

Um definitivo incremento se processa no percurso de vida de Paulo Emilio Salles Gomes até a década seguinte: o crítico, conferencista, debatedor, conservador da cinemateca agrega ainda mais valor à sua presença no campo social com a publicação do livro Humberto Mauro, Cataguases e Cinearte, tese de doutorado focalizando o período de formação do cineasta Humberto Mauro entre a cidade de Cataguases e o ingresso nos estúdios da Cinédia. Desta forma, ocupa uma posição de destaque como professor de cinema da UNB e da USP, como personalidade irradiadora de pesquisas e como orientador de dissertações e teses. A figuração do crítico também ganha novo contorno com as famosas sínteses presentes nos textos O Cinema no século, de 1970, e Cinema: trajetória no subdesenvolvimento, de 1973. 
Sem falar na transformação extemporânea em ficcionista de destaque com a publicação, em 1976, um ano antes da sua morte, do livro Três mulheres de três ppps.

Esta trajetória e a difusão das suas provocações no Suplemento Literário justificam o desejo de proximidade com as suas concepções e ideias por muitos realizadores, mas sobretudo por cineastas do Cinema Novo e de outras vertentes do cinema moderno do período. A remissão constante a artigos de Paulo Emilio por produtores e cineastas - a exemplo de David Neves, Glauber Rocha, Jean-Claude Bernardet e Gustavo Dahl - colocou o crítico numa posição incômoda: de um lado, chamado a ratificar as afirmativas; por outro, instado a prosseguir a sua constante reelaboração de concepções pré-estabelecidas. Enfim, o autor foi colocado perante as suas próprias citações em passagens pinçadas de seus próprios textos.

Atualmente, um estudo que se interessa pelas questões envolvidas no pensamento de um crítico-historiador, a exemplo de Paulo Emilio Salles Gomes, deve se colocar diante da compreensão da insuficiência ou erro da noção de autoria como aparecimento do sujeito pleno. Desde o "deslocamento Copérnico" sugerido por As Palavras e as coisas e A arqueologia do saber, de Michel Foucault, é necessário pensar o autor como o lugar vazio em que os enunciados se produzem, ou seja, como instância de emergência da função-autor. A construção do ser racional "autor" é uma das características da função-autor. Esta, por sua vez, é “característica do modo de existência, de circulação e de funcionamento de alguns discursos no interior de uma sociedade" (Foucault, 1997: 46) ${ }^{2}$.

Giorgio Agamben desdobrou a problemática da autoria para Foucault tendo como base a diferença entre a conferência francesa e a da Universidade de Buffalo, mas sobretudo o texto A Vida dos homens infames. A contribuição principal diz respeito à ideia de vidas "postas em jogo" e, afinal, do direcionamento da compreensão do autor para a sua representação, por assim dizer, teatral. Não é o caso de se tratar de biografias ou de retratos, mas dos textos que bordejam uma obra que continua irrealizada sobre o não-dito e o nãoescrito "Uma subjetividade produz-se onde o ser vivo, ao encontrar a linguagem e pondo-se

\footnotetext{
${ }^{2}$ Além da conferência $O$ que é um autor?, ver também, na mesma organização, A escrita de si e A Vida dos homens infames. $\mathrm{O}$ trabalho de Michel Foucault é a referência quando se trata de uma problematização sobre autoria. A abordagem sobre a arte da existência, do sujeito ético que age sobre si e se transforma, está disposta no estudo do terceiro volume da História da sexualidade - o cuidado de si (Foucault, 1985: 35-73). O exame sobre a degenerescência na prática da interpretação dos sonhos (onirocrítica) de aphrodisia - ao mesmo tempo sobre o ato, o prazer e o desejo - fornece elementos para a compreensão sobre as técnicas, os conceitos e as perspectivas do cuidado de si. A prática está intrinsecamente ligada à criação de um ambiente para o jogo de trocas e de obrigações com o outro: trata-se não somente de um "exercício da solidão", mas de uma prática social que fornece elementos constitutivos da subjetividade (Foucault, 1985: 72). É evidente, aqui, a ligação entre linguagem e sexualidade (Barthes, 1988).
} 
nela em jogo sem reservas, exibe em um gesto a própria irredutibilidade a ela. Todo o resto é psicologia e em nenhum lugar na psicologia encontramos algo parecido com um sujeito ético, uma forma de vida" (Agamben, 2007: 63).

Esta figuração de subjetividades e modelos de subjetividade tem em conta a biopolítica contemporânea, onde o sujeito opera sua conformação do "Eu" como campo de luta. É na diferença entre a langue e a parole que esta teoria dos enunciados instala o seu canteiro de trabalho ${ }^{3}$. Nesta esteira, Agamben retoma o significado do termo "autor" no penúltimo livro até agora publicado na série Homo Sacer: O que resta de Auschwitz. Originalmente, o autor era aquele que intervinha no ato de um menor, pois este não seria capaz de realizar ato juridicamente válido. Também foi compreendido, entre os antigos, como o "vendedor" dentro de um ato de transferência de propriedade, ou aquele que "aconselha ou persuade". Afinal, o autor é a testemunha. O que é comum nos significados é a ideia de ato imperfeito no qual, na relação entre os sujeitos, um seria o autor do outro, recebendo do alheio "o impulso ou complemento que lhe permite passar ao ato" (Agamben, 2008: 149$151)$.

Se é verdade que todo ato de palavra, assim como todo ato poético, comporta uma parcela de dessubjetivação, que anula antes de refazer a criação do "Eu", a passagem da língua ao discurso será sempre um ato paradoxal. Como diz Agamben: "A enunciação não se refere, portanto, ao texto do enunciado, e sim ao fato de ter lugar, e o indivíduo pode pôr em funcionamento a língua sob a condição de identificar-se no próprio acontecimento do dizer, e não no que, nele, é dito" (Agamben, 2008: 120). Longe de identificarmos o texto como o conteúdo sobre o qual se funda uma positividade, pensaremos o texto como a discursividade onde são jogadas posições.

\section{Correção de posições e apelo ao diálogo}

Antes de abordarmos o artigo $O$ cinema no século, será importante resgatar o gesto de autofiguração que a escrita de Paulo Emilio perfazia na intervenção no jornal Brasil, Urgente. O periódico foi um semanário organizado e publicado em 1963 e 1964 a partir da aproximação entre evangélicos e católicos progressistas, intelectuais e jornalistas que encontravam barreiras em suas próprias instituições para levar adiante esforços de engajamento político e de divulgação e acesso à informação. A imantação das discussões

\footnotetext{
${ }^{3}$ A retomada das investigações de Benveniste (2005 e 2006) foi de muita valia nesta reflexão. As produções de sentido e o hiato entre semiologia e semântica funcionam como pontos de balizamento para as lógicas de figuração da autoria.
} 
políticas fez orbitarem intelectuais, estudantes e sindicalistas ao redor de atividades de discussão que ocorriam sob os auspícios ou no próprio convento dominicano localizado no bairro de Perdizes, em São Paulo. A insatisfação com as tradicionais correntes de esquerda e a necessidade de encontrar linhas de ação no contexto nacional-desenvolvimentista, de grande agitação e confusão ideológicas, levou cristãos leigos e figuras não envolvidas com o credo religioso a se interessarem pelas ideias e articulações coordenadas entre frades que depois comporiam um grupo visado pela ditadura civil-militar.

A técnica da escrita e a condução dos temas abordados no Brasil, Urgente por Paulo Emilio definem um conjunto de escritos e uma articulação de ideias muito próprios, que antecipam a proposta do crítico de se pôr em cena, mas portando máscaras inesperadas. A intervenção está concentrada em cerca de dezoito semanas, de março a julho de 1963, e voltava-se para uma comunidade de leitores que Paulo Emilio talvez tenha imaginado distanciada dos meios que seus textos frequentavam. Daí a oportunidade de se reprogramar. Não é sem certo exagero que podemos dizer que estamos diante de alguém disposto a passar uma borracha não só em preconceitos, ideias pré-formadas, pontos de vista estabelecidos, vieses ideológicos exatos, mas também disposto a reposicionar a sua própria figura. Diante de um novo público leitor, diante de um projeto novo de imprensa alternativa, o crítico mascarase para reentrar em cena.

Há uma relação desviante com o assunto que é objeto de cada crítica. Tal operação segue lado a lado com o questionamento da própria posição enquanto crítico, se é que podemos realmente classificar tais textos seguindo a definição de crítica strictu sensu, uma vez que já no segundo número do jornal o autor fala em "crônica". A figura vai se desvelando aos poucos, vai tirando o véu da sua própria narrativa biográfica, que só importa se é imprescindível para determinar algum aspecto do argumento de maneira mais enfática. Isto acaba acontecendo no quarto texto, quando finalmente fala do próprio trabalho, dedicado à sustentação de uma cinemateca no Brasil, com o objetivo de responder uma leitora que o questionara como alguém poderia não ser tanta coisa ao mesmo tempo, como constava na sua apresentação no primeiro texto da intervenção.

Neste texto inaugural, o crítico toma um caminho contrário ao arroubo afirmativo dos jovens críticos e cineastas, dirigindo seus petardos contra os críticos especializados em cinema, utilizando-se de fina ironia, falando a leigos e religiosos, operários e estudantes. $\mathrm{O}$ primeiro artigo insiste também numa abertura ao diálogo. O título é "Começo de conversa". 
cinema. Mas não sei. Não darei conselhos e é claro, não farei moral. Também não farei política porque não dou para a cousa. Já tentei, há muito tempo e fracassei. Política é ter certezas, ou fazer que as tem, e procurar impingí-las aos outros. Minhas eventuais certezas são por demais genéricas ou particulares e não valem para a ação. Posso também assegurar que aqui neste canto não se refugiará um chamado especialista em cinema. Não pretendo influenciar ninguém, mas confesso que tenho horror pelos especialistas em cinema e que só os leio por obrigação, e olhe lá. Não perdôo ao crítico cinematográfico o fato de seus artigos serem sistematicamente mais cacetes do que as fitas que comenta. Também não levo a sério a história do crítico ser intermediário útil entre as fitas e os espectadores. Na realidade os críticos passam a vida se entrelendo e se entreolhando. No fundo só eles se entendem e o público tem pouco ou nada a ver com o que dizem nas linhas e sugerem nas entrelinhas, já que lhes apraz muito a alusão e o subentendido (GOMES, 1963: 1) ${ }^{4}$.

O jogo de máscaras já começou e se desdobra com um aviso, mais adiante: "sou um homem completamente sem princípios, pelo menos em matéria estética. Em outras matérias, deixemos o futuro falar." A nota é acompanhada do convite ao diálogo; Paulo Emilio diz gostar de conversa, ser bom ouvinte, e torce para receber muitas cartas sobre o que seria dito naquele espaço.

Estabelecido o primeiro patamar, fugidio, de tematização e posicionamento, a resposta à carta de uma leitora serve como motivação para um rearranjo formal, no quarto artigo, quatro semanas depois, da estratégia do crítico de não identificar-se cabalmente e a priori. Assim, há mudança que conduz a negativa em falar de si para a tática oposta de afirmação peremptória e comprometida com princípios pessoais que se baseiam numa solene missão de vida. Ocorre a explicitação do engajamento com as atividades de conservador da cinemateca. Enfim, ele reelabora o lugar de fala a partir da elucidação daquilo de que cuidava - a Fundação Cinemateca Brasileira.

Tal estratégia sobre o falar de si ocorre mesmo no espaço no qual deixara de escrever desde 1962, no Suplemento Literário do jornal O Estado de São Paulo. Paulo Emilio publica em 1965 o famoso texto autobiográfico Um discípulo de Oswald em 1935. Não examinaremos este material que teria interesse próprio e seria mais dirigido aos leitores do campo cinematográfico e literário, muito mais informados sobre a trajetória do crítico. Basta apenas ressaltar que se trata novamente de um artigo também surpreendente por construir a ideia de constante exercício da imaginação sobre o passado mítico ("a idade do ouro") do interesse sobre o modernismo, mas que serve como motivo para o reposicionamento da sua própria figuração.

\footnotetext{
${ }^{4}$ Uma reprodução deste artigo, mais acessível, se encontra em CALIL \& MACHADO (1986: 223 e 224).
} 


\section{Projeções teóricas do cinema no século}

Em linha com esta renovação da própria figuração na esfera pública está o texto $O$ cinema no século, que veio à luz na capa do Caderno B do Jornal do Brasil, em 27 de dezembro de 1970. É importante percebermos a oportunidade da efeméride que representa a data, um dia antes do famoso 28 de dezembro no qual os irmãos Lumiére realizaram a sessão paga no Grand Café em Paris.

O texto perfaz o caminho inverso da proposição da coluna de Brasil, urgente, pois elabora na sua primeira parte uma narrativização da própria família do autor como público cinematográfico. Ou seja, na coluna de cinema em Brasil, urgente o crítico saiu do zero para a informação sobre si, levando em conta que haveria a oportunidade de estabelecer um diálogo ao longo das edições do semanário. Na rápida mas densa intervenção no Jornal do Brasil, Paulo Emilio parte de motivos do seu próprio trabalho como crítico e especialista de cinema, além da menção à geração de espectadores da sua própria família, para abandonar tal referência em seguida.

$\mathrm{O}$ assunto do texto é a própria história do cinema, todavia abordada por um ângulo novo, raro até então mesmo na teoria do cinema, que é o do público cinematográfico. Em suma, a tese é a de que para se entender as potencialidades de um novo cinema - muito mais plural e livre - é preciso pensar o fenômeno no século tendo como base as gerações de espectadores e a progressiva desimportância da mídia de massa diante de outros consumos ou lazeres.

Vejamos o desenrolar dos argumentos com a técnica da escrita que é fugidia e surpreendente, como pudemos perceber no exemplo da apresentação à intervenção de Brasil, urgente e como pode ser verificado em textos biográficos que o próprio Paulo Emilio produziu sobre figuras como Plinio Sussekind Rocha, Andre Maulraux e Arnaldo Pedroso D’Horta $^{5}$.

No início do texto o crítico traz a pergunta sobre quando e onde nasceu o cinema, partindo da conhecida afirmação sobre a sessão dos irmãos Lumière em Paris no ano de 1895. Logo em seguida, contudo, recusa este tipo de abordagem que remeteria a uma discussão sem fim que ele reputa de pouco interesse. O melhor seria perguntar-se sobre o público cinematográfico em termos de gerações de espectadores. E para isso, conclui, os melhores

\footnotetext{
${ }^{5}$ A redação deste artigo iniciou-se com base neste tema central de materiais que estão entre os mais bem escritos textos de Paulo Emilio. Um exame anterior sobre eles, que nos serviu de guia, foi o estudo sobre o biografismo e o trabalho da imaginação na escrita do autor: A imaginação como elemento político (Schwarz, 1986).
} 
exemplos seriam os familiares. Vejamos o que dizem os únicos três parágrafos nos quais ele se dispõe a tratar de si e da sua própria linha geracional.

Os melhores exemplos são os familiares. Cada vez que alguém falava de uma fita ao meu avô, invariavelmente respondia que já tinha visto. Começava ele a adquirir uma reputação de fanático de cinema, até que se esclareceu a significação do "já vi". Fora uma vez ao cinema para saber do que se tratava, considerou-se satisfeito e nunca mais voltou.

Meu pai devia ser um espectador distraído, pois entraram para o anedotário familiar as perguntas que fazia durante a projeção. Os programas eram duplos. Às vezes, ele se interessava por um ator, em geral cômico, e se queixava porque o ator tardava a reapareceer na tela. É que já estávamos na segunda fita.

Não sei se os meus filhos eventuais e netos naturais são fãs de cinema. Mas é inútil pesquisar, pois já ficou claro que não pertenço a uma dinastia de espetadores. Eu próprio nunca fui fã. (GOMES, 1970: 1)

Ora, a proposta de depoimento pessoal a partir da própria família é abandonada em seguida. Uma vez que o seu próprio exemplo não serve, o que vem à baila de modo bem mais alongado é o retrato de 40 anos de público cinematográfico de uma família de fãs que conhecera em uma de suas palestras sobre cinema no interior de São Paulo. Durante a palestra, ele conta que, a cada momento da sua abordagem, um rosto da primeira fila, heterogênea em idade e interesses sobre os períodos, se iluminava diante do panorama exposto. Depois ele descobriria que se tratava mesmo de uma família de fãs completos", como diz, destes que arregimentavam amigos para ir ao cinema, liam revistas e colecionavam fotografias.

Naquela época eu ainda nutria ilusões a respeito da eficácia dos panoramas históricos amplos e ordenados. E era nessa linha que a minha fala se desenvolvia. Sempre procurei eleger algumas caras do público e a elas me dirigir especialmente. Assim foi que, naquela noite, escolhi o grupo que despertara a minha atenção.

Cada momento da minha exposição encontrou entre eles verdadeiros interlocutores, tal a presteza com que reagiam aos comentários e informações. Até 1920, dialoguei com um velho espigado. Depois foi a vez de uma senhora bem quarentona. [...]. Quando cheguei aos anos 50, o interlocutor era um jovem. (GOMES, 1970: 1)

Há o prolongamento do contato para um almoço no dia seguinte. O crítico obteve mais informações sobre aquele desdobramento geracional e um dado chamou muito a sua atenção: cada geração defendeu ardorosamente o "seu" cinema, quer dizer, o tempo em que assistia a dois ou três filmes por semana; e também, segundo os depoimentos, cada geração experimentou o colapso do próprio interesse como público e cada vez mais cedo: o avô antes dos 40 anos, a filha antes dos 30 e o jovem não muito depois dos vinte anos. 
O desdobramento lógico é o de que os próximos componentes daquela família não mais comporiam a dinastia dos fãs. Ao contrário do que se imaginava, não havia um pleno desenvolvimento para a quarta geração.

Em seguida, procura explicar as razões do fenômeno e se utiliza do exemplo do público norte-americano, pelo seu desenvolvimento harmonioso, sistemático e coerente. Mesmo com os desafios da entrada do automóvel e do final de semana com beisebol, a massa consumidora se manteve fiel à sala escura por décadas. A Lei Seca e o rádio também se constituíram novos desafiantes, uma vez que seriam motivos de retenção do público em casa. Ainda assim, o fenômeno cinematográfico ainda manteve a vitalidade que o caracteriza no arco temporal que chega até a década de 1950. Todavia, o rádio anunciava o desafio que perturbaria a sua solidez do fenômeno, pois antecipava o advento da televisão.

Paulo Emilio utiliza o caso do fenômeno cinematográfico norteamericano como exemplo válido para o entendimento do que aconteceu com o ocidente europeu em geral, não sem a ressalva de que descontaria ou atenuaria as peculiaridades de cada local.

Os primeiros historiadores do cinema escreviam com a emoção de contemporâneos do nascimento de uma nova arte. Não somos propriamente testemunhas de sua morte, mas assistimos ao fim da conjuntura que a condicionou. Estamos na situação privilegiada de espectadores e personagens de um encerramento. Houve nascimento, desenvolvimento e morte de um cinema e seu público. (GOMES, 1970: 1)

\section{O futuro do pretérito: o cinema na era da televisão}

Evidentemente, está em questão o arco complementar, futuro em relação à escrita do texto, das décadas seguintes do século XX. A operação de retrospecção em modo panorâmico acaba, portanto, por mostrar seu característico teor de descontinuidade. No momento da escrita, o crítico apontava para o fato inquestionável de que o fenômeno cinematográfico mudara qualitativamente e que tal mudança se verificava na constituição mesma do tradicional espectador de cinema. Emergia, segundo o seu entendimento, um novo fenômeno cinematográfico, livre das injunções e dos interesses que conduziam o outro fenômeno. Por ser novo, tal fenômeno deveria ser compreendido como tal, a partir de suas próprias características, e afinal esta é a tese central do denso artigo.

Cabe a ele descobrir a sua função, suscitar e organizar seus espectadores, em suma, inventar-se. O mecanismo de auto-invenção exige a criação de um sistema próprio de referências e vocabulário. As expressões independente, 
underground, marginal etc, etc., não são um bom sinal. O cinema dependente morreu, o ground ruiu, esvaiu-se o texto que delimita a margem. (GOMES, 1970: 1)

O trecho final do artigo examinado coloca algumas consequências desta nova luz compreensiva lançada sobre o cinema no século XX, luz cujo espectro apresenta uma evidente provocação àqueles que imaginavam uma luta infindável contra a tal dominação norte-americana. A batalha ideológica com denúncias contra a dominação pelo modelo estadunidense de comércio encontrava-se caduca e mesmo este aspecto é considerado uma abertura de possibilidades. Curiosa a operação do crítico e teórico de cinema, de conferir miudeza ao seu objeto, de repô-lo em outras dimensões ao seu leitor.

$\mathrm{O}$ que dizer de uma abordagem que, menos de 20 meses depois das revoltas estudantis do ano de 1968, procurava desmistificar o conteúdo de algumas das demandas que pareciam muito evidentes? Aliás, até nos dias de hoje, muito do posicionamento político de cineastas e ativistas refere-se ao fantasma redivivo do filme de entretenimento e distração importado. Daí a atualidade e permanência do artigo examinado, não só em termos do estabelecimento de evidentes marcos temporais do fenômeno cinematográfico no século XX e da escrita de si pelo crítico de cinema.

O que o cinema atual tem de bom deriva da sua progressiva desimportância como fenômeno social. Se, em alguns países filmes políticos agudíssimos são produzidos e exibidos, é porque isso não mais importa. A mesma reflexão se aplica às audaciosas proposições morais em curso ou à irupção da linguagem experimental. Se o terreno escolhido fosse o da televisão, tudo importaria a ponto de não acontecer. Organismos privados e públicos ainda protestam e censuram fitas, mas é porque cumprem à risca a missão de confundir o ontem e o hoje. [...]

Poderia acontecer que durante os últimos 30 anos que restam ao século, o novo fenômeno cinematográfico participasse, mesmo modestamente, do pesado encargo que espera a humanidade: fazer do terceiro milênio da era cristã algo menos bestial do que foram os dois primeiros, com suas classes e guerras. (GOMES, 1970: 1)

Há, portanto, uma proposição muito ampla sobre a história tendo como base o cinema e a construção de uma narrativa de si. Através da consideração da trajetória do crítico Paulo Emilio Salles Gomes na mais recente modernidade cinematográfica, examinada a partir da questão do autoria e dos processos de subjetivação, foi possível compararmos esta escrita de si em textos dispostos nos jornais Brasil, urgente (1963) e Jornal do Brasil (1970). Tais materiais sinalizam um objeto pouco abordado - o público cinematográfico - e o desejo de 
diálogo para além do restrito campo da crítica cinematográfica. Trata-se do exercício de refiguração da imagem de si, de questionamento da imagem da autoridade, de exame histórico-estético e de predição com cunho político pelo crítico e pesquisador. Ao perceber no mais recente e moderno o signo do arcaico, Paulo Emilio foi de fato um contemporâneo. Viu escuro onde aparentemente só havia luz e inseriu no tecido do presente uma divisão entre vivido e não-vivido. "A atenção dirigida a esse não-vivido é a vida do contemporâneo" (Agamben, 2009: 70).

\section{Referências Bibliográficas}

AGAMBEN, Giorgio. O que é contemporâneo? e outros ensaios. Cahpecó-SC Argos, 2009. . O que resta de Auschwitz. Homo Sacer III. Boitempo: São Paulo, 2008.

. “O Autor como gesto”. In: Profanações. São Paulo: Boitempo, 2007.

AUMONT, Jacques. Moderno? Por que o cinema se tornou a mais singular das artes? Campinas, SP: Papirus, 2008.

BACHELARD, Gasto. A Formação do espírito científico. $1^{\mathrm{a}}$ ed. Rio de janeiro: Contraponto, 1996.

BENJAMIN, Walter. "Rua de mão única". Obras escolhidas (v. II), $5^{\mathrm{a}}$ ed. $3^{\mathrm{a}}$ reimp. São Paulo: Brasiliense, [1985] 2000, p. 9-70.

. "A obra de arte na era da sua reprodutibiliade técnica". In: Magia e técnica, arte e política. Obras escolhidas (v. I), $7^{\mathrm{a}}$ ed. 10 ${ }^{\mathrm{a}}$ reimp. São Paulo: Brasiliense, [1984] 1996, p. 165196.

CALIL, Carlos Augusto \& MACHADO, Maria Teresa (org.). Paulo Emílio: Um intelectual na linha de frente. São Paulo: Brasiliense; Embrafilme, 1986.

FOUCAULT, Michel. O que é um autor. $3^{\text {a }}$ ed. Lisboa: Passagens, 1997.

História da sexualidade, 3: o cuidado de si. Rio de Janeiro: Edições Graal, 1985.

GOMES, Paulo Emilio Salles. "Cinema: trajetória no subdesenvolvimento". Argumento, Revista Mensal de Cultura. São Paulo, no 3, out. 1973.

1. . “O Cinema no século”. Jornal do Brasil, Rio de Janeiro, 27 dez. 1970. Caderno B. p. . "Começo de conversa”. Brasil, Urgente, São Paulo, 17 mar. 1963. nº 1.

KRACAUER, Sigfried. O Ornamento da massa. São Paulo: Cosac Nayf, 2009. 
SCHWARZ, Roberto. "A imaginação como elemento político". In: CALIL, Carlos Augusto \& MACHADO, Maria Teresa (org.). Paulo Emílio: Um intelectual na linha de frente. São Paulo: Brasiliense; Embrafilme, 1986, p. 189-194.

XAVIER, Ismail. Sétima Arte: um culto moderno. São Paulo: Perspectiva; Secretaria da Cultura, Ciência e Tecnologia do Estado de São Paulo, 1978. 